\title{
Editorial
}

\section{CONSEQUENCES OF LEPROSY AND SOCIO-ECONOMIC REHABILITATION}

Leprosy once affected every continent and it has etched a terrifying image in history and human memory of mutilation, rejection and exclusion from society ${ }^{1}$

As we approach the end of the millennium, leprosy is no longer the dreaded disease that it used to be, and leprosy patients face a far better future than ever before. However, the social image of leprosy is not greatly changed in many parts of the world; this is all too well reflected in the attitude of the community, particularly towards individuals disabled due to the disease. $^{2}$

Even today, social stigmatization is frequent so that affected persons with clear signs of chronic manifestations are of ten unable to work or to marry, they become dependent for care and financial support, leading to insecurity, shame, isolation and consequent economic loss. ${ }^{3}$

All the above statements are from annual status reports of the World Health Organisation (WHO), dealing with the progress in reaching the goal of elimination of leprosy as a public health problem. All these documents continue to underline the need for strengthening action against social, economic and psychological consequences of the disease, not only for persons having the disease but also for whole families and communities. ${ }^{4}$

Similar statements and recommendations have been made in all international congresses on leprosy and publications of the Medico-social Commission of the International Federation of -anti-leprosy organizations (ILEP) over the past few decades.

The strategies proposed for dealing with these human consequences of leprosy include: - Disability assessment, prevention and management, using simple cost-effective approaches and integration into a routine leprosy programme, not only for benefit of patients but also for the credibility of the programme. Supportive activities to core activities for reaching the elimination goal include patient and family counselling, community education, adequate referral systems and promotion of social and economic integration. ${ }^{1}$

- There will be a continuing need to care for those patients for whom dapsone and MDT came too late, and who accordingly will live out their lives with grievous disabilities. ${ }^{2}$

- Regarding rehabilitation of persons affected by leprosy, the strategy of choice is community based rehabilitation (CBR). ${ }^{1}$

- The strategy for leprosy related disabilities should be elaborated at country level with full participation of the health sector, as well as other sectors, NGOs (non-governmental organizations) and community leaders. ${ }^{3}$ 


\section{Progress made and challenges}

In spite of this unanimity about the need for adopting these strategies, so far the progress made has been quite limited.

PREVENTION OF DISABILITIES (POD), PHYSICAL, PSYCHOLOGICAL AND SOCIO-ECONOMIC REHABILITATION ACTIVITIES IN LEPROSY CONTROL PROGRAMMES

Over the last 2 decades, more than 10 million persons have been cured of their infection through MDT. Among them, estimates of persons with physical disabilities at the time of diagnosis vary between 10 and $20 \%$. If we consider the difficulties in collecting such data at national level and the disabilities arising after starting MDT, the numbers are probably much higher. This means that there could be $2-4$ million persons with grade 1 and grade 2 leprosyrelated disabilities (impairments) in the world. However, this classification does not give any idea of specific rehabilitation needs related to physical impairments and disabilities. Similar information about psychological and socio-economic rehabilitation needs is almost nonexistent at national or subnational levels. At national level, hardly any leprosy control programme has a clear strategy for POD and rehabilitation.

Even in many smaller projects managed by NGOs, the last 2 decades have seen a gradual decrease in attention towards rehabilitation activities. The decision-makers in such projects and many supporting organizations are often doctors, which could mean more attention directed towards treatment aspects and less towards rehabilitation activities, especially for socio-economic aspects.

LEPROSY-AFFECTED PERSONS IN OLD LEPROSARIA AND LEPROSY COLONIES

The last 2 decades have seen gradual closing down of old leprosaria and support for such structures is seen increasingly as unproductive and unimportant. Persons living in such structures are usually elderly, from the pre-MDT era. Some recent data from countries such as Vietnam, India and China shows that there are many such existing structures with significant number of persons living there. ${ }^{5}$ National leprosy programmes may not have updated information about these structures and about persons living there.

CBR PROGRAMMES AND LEPROSY-AFFECTED PERSONS

Not all countries have CBR programmes. Where there are, these are not national level CBR programmes and most are limited to a few geographical areas. Even in such limited CBR projects, leprosy-affected persons may not be included automatically. When asked the reasons for this exclusion, the most common reason cited by CBR programme managers is that the leprosy control programme looks after rehabilitation needs of leprosy-affected persons. Sometimes, this may also denote deep-rooted prejudices against leprosy. However, there are some CBR programmes involving leprosy-affected persons as in Ghana, Vietnam and Indonesia.

MAINSTREAMING IN EXISTING REHABILITATION SERVICES AND NETWORKING WITH OTHER EXISTING RESOURCES AND GENERAL DEVELOPMENT PROJECTS

Unfortunately, disabilities and rehabilitation programmes are not seen as a priority in any country. Barely $10 \%$ of disabled persons have access to any rehabilitation services. ${ }^{6}$ The access is even less in rural areas, where the majority of leprosy-affected persons live. There have been attempts to introduce rehabilitation as integral part of Primary Health Care (PDC) services, but this remains a challenge for most developing countries. 


\section{Other recent developments}

Organizations working in the field of disability and development have long been promoting the active involvement of beneficiaries in all aspects of project activities, starting from identification of needs, definition of strategies, activities implementation and their monitoring. Traditionally, projects dealing with rehabilitation of leprosy-affected persons often continue to be managed by professionals with no or limited experience of leprosy-affected persons. This is gradually beginning to change and needs to be further reinforced.

The launching of new associations representing leprosy-affected persons, for example IDEA International and its country organizations, has helped in focussing more attention towards other aspects of leprosy-related issues, including the use of specific terms by leprosy professionals (for example, using the term leprosy-affected person rather than ex-patient, and not using terms like leprosy victim or leprosy sufferer).

The enormous gains made by many leprosy control programmes in eliminating leprosy as a public health problem present special opportunities for existing vertical leprosy staff and infrastructures to promote new activities for physical, psychological and socio-economic rehabilitation for leprosy-affected persons and for persons with disabilities.

\section{Areas of future action}

It may not be realistic to expect national leprosy control programmes suddenly to show greater interest and initiatives related to rehabilitation needs of leprosy-affected persons. Though attempts to promote holistic rehabilitation of leprosy-affected persons have had limited impact up to now, there are four specific areas in which leprosy-related projects and organizations can make significant contributions in the coming years:

- Reviewing their existing strategies for POD and socio-economic rehabilitation, including definitions of simple indicators for measuring their impact.

- Defining new strategies of information and capacity building aimed at primary health care personnel for promoting rehabilitation activities.

- Advocacy and awareness creating among CBR programmes and NGOs operating in the field of general development, about the needs of leprosy-affected persons.

- Promoting greater participation of leprosy-affected persons in all activities and strengthening their organizations.

\section{References}

${ }_{1}$ Global strategy for the elimination of leprosy as a public health problem. HO/CTD/LEP/94.2.

2 Action programme for elimination of leprosy. Status Report 1998, WHO/LEP/98.2.

3 Elimination of leprosy. Status Report 1999 (draft).

4 Towards elimination of leprosy. WHO/CID/LEP/91.1.

5 Personal communications, Alex Joucot, DFB/Vietnam and P.K. Gopal, IDEA/India.

6 Prejudice and dignity. Einar Helander, UNDP, 1999.

*Italian Association Amici di Raoul Follereau (AIFO),

SUNIL DEEPAK

Bologna, Italy

**International Association for Integration,

P.K. GOPAL

Dignity and Economic Advancement (IDEA), India

$\dagger$ German Leprosy Relief Association (DAHW),

ERNST HISCH

Wurzburg, Germany 